\title{
MODELLING OF COMPACTION OF TITANIUM COMPOSITE POWDERS
}

\author{
D. I. Kryuchkov ${ }^{1}$, A. G. Zalazinsky ${ }^{1}$, I. M. Berezin ${ }^{1}$, O. V. Romanova ${ }^{2}$ \\ ${ }^{1}$ Institute of Engineering Science, Ural Branch of the Russian Academy of Sciences, 34 Komsomolskaya st., \\ Ekaterinburg, Russian Federation \\ ${ }^{2}$ Institute of Metallurgy, Ural Branch of the Russian Academy of Sciences, 101 Amudsena st., 101 Ekaterinburg, Rus- \\ sian Federation \\ ${ }^{*}$ Corresponding author. E-mail: kru4koff@bk.ru; address for correspondence: ul. Komsomolskaya, 34, 620049, \\ Ekaterinburg, Russian Federation. Tel.: +7 (343) 374-50-51; fax: +7 (343) 374-53-30
}

The quality of finished products is determined at the stage of compaction. High-pressure cold compaction sometimes fails to provide the coalescence of VT-22 high-strength titanium alloy powder particles. Particle coalescence is governed by mechanical characteristics, the spherical particle shape and hard oxide on the particles of the VT-22 powder. This results in the low strength workpieces. To ensure the strength of a compact, powder additives with more plastic properties are used. Simulation is applied to find an optimum additional powder and its volume. The process of compaction is simulated with the use of a representative volume element for a composite made of the VT-22 and PTM-1 powders. The forming and coalescence of particles are represented in uniform triaxial and uniaxial compression. It is shown that the increase in the percentage of VT-22 to more than $50 \%$ in the mixture prevents the uniform spreading of the more ductile component PTM1. The parameters of the modified Drucker-Prager Cap model are identified for $50 / 50$ and $75 / 25$ VT-22 and PTM-1 powder composites. Compaction in a closed container is simulated. Problems are solved with the application of program packages developed for Abaqus. Experiments on compacting and breaking workpieces made of the pure powders and their two mixtures are made to validate the adequacy of the solution results.

Keywords: powder, titanium, compaction, simulation, coalescence of powder particles.

\section{References}

1. Froes F.H., Smugersky J.E. Poweder metallurgy of titanium alloys. The metallurgical society of AIME Publ., 1980. 263 p.

2. $\quad$ Froes F.H., Eylon D., Bomberger H.B. Powder metallurgy of titaniumium alloys - a review. Titanium Technology: Present Status and Future Trends, 1985, pp. 49-59.

3. Abkowitz S., Abkowitz S.M., Weihrauch P.F., Wells M.G. Low cost PM manufacture of titanium alloy components for fatique critical application. Proc. The Third International Conference on Powder Metallurgy in Aerospace, Defense, and Demanding Applications, Princeton, NJ, 1993, pp. 241.

4. Moxson V.S., Senkov O.N., Froes F.H. Production and applications of low cost titanium powder products. The International Journal of Powder Metallurgy, 1998, vol. 34 (5), pp. 45-53.

5. Kari S., Berger H., Rodriguez-Ramos R., Gabbert U. Computational evaluation of effective material properties of composites reinforced by randomly distributed spherical particles. Composite Structures, 2007, vol. 77, pp. 223-231.

6. Mesarovic S.D. Micromechanical modelling of the compaction of low density composite powders. Metalurgija - Journal of Metallurgy, 2005, vol. 11(1), pp. 1-21.

7. Sridhar I., Fleck N.A. Yield behaviour of cold compacted composite powders. Acta materialia, 2000, vol.48, pp. 3341-3352.

8. Kryuchkov D.I., Zalazinsky A.G. Hybrid modelling complex for optimization processes of extrusion of non-uniform materials. Vestnik kompjuternyh i informacionnyh tehnologij, 2013, no. 9, pp. 22-28. (In Russian). 
9. Leon L., Mishnaevsky Jr. Automatic voxel-based generation of 3D microstructural FE models and its application to the damage analysis of composites. Materials Science and Engineering, 2005, vol. 407, pp. 11-23.

10. Shen H., Brinson L.C. Finite element modeling of porous titanium. International Journal of Solids and Structures, 2007, vol. 44, pp. 320-335.

11. Kushch V.I., Podoba Ya.O., Shtern M.B. Effect of micro-structure on yield strength of porous solid: A comparative study of two simple cell models. Computational Materials Science, 2008, vol. 42, pp.113-121.

12. Ogbonna N., Fleck N.A. Compaction of an array of spherical particles. Acta Metallurgica et Materialia, 1995, vol.43, pp. 603-620.

13. Berezin I.M., Zalazinskiy A.G. Identification of the determinative correlations of plastically compressed materials. Fundamentalnye issledovanija, 2013, no. 8, pp. 19-23. (In Russian).

14. Johnson G.R, Cook W.H. Fracture Characteristics of Three Metals Subjected to Various Strains, Strain Rates, Temperatures and Pressures. Eng. Fract. Mech, 1985, vol. 21, pp. 31-48.

15. Bogatov A.A. Mekhanicheskie svoistva i modeli razrucheniya metallov [Mechanical properties and models of fracture of metals]. Ekaterinburg, GOU VPO UGTU-UPI Publ., 2002, 329 p. (In Russian).

16. Semenov A.P. Skhvatyvanie metallov [Adhesion of metals]. Moscow, Mashgiz Publ., 1958, 280 p. (In Russian).

17. Kolmogorov V.L. Mekhanika obrabotki metallov davleniem [Mechanics of metal forming]. Ekaterinburg, UGTU-UPI Publ., 2001, 836 p. (In Russian).

18. Kolmykov V.L., Glazunova M.Ju., Zalazinsky A.G. Drawing a thin wire made of titanium for suture materials. Izvestija VUZov. Cvetnaja metallurgija, 2002, no. 3, pp. 66-69. (In Russian).

19. Kolmykov V.L., Zalazinsky A.G. Deposition of oxide coatings for wire drawing of difficultto-deform materials. Uprochnjajushhie tehnologii i pokrytija, 2007, no. 6, pp. 15-18. (In Russian). 


\title{
МОДЕЛИРОВАНИЕ ПРОЦЕССОВ КОМПАКТИРОВАНИЯ ТИТАНОВЫХ КОМПО- ЗИТОВ ИЗ ПОРОШКООБРАЗНОГО СЫРЬЯ
}

\author{
Д. И. Крючков ${ }^{1}$, А. Г. Залазинский ${ }^{1}$, И. М. Березин ${ }^{1}$, О. В. Романова ${ }^{2}$ \\ ${ }^{I}$ Федеральное государственное бюджетное учреждение науки Институт машиноведения Уральского отделе- \\ ния Российской академии наук, ул. Комсомольская, 34, Екатеринбург, Российская Федерация \\ ${ }^{2}$ Федеральное государственное бюджетное учреждение науки Институт металлургии Уральского отделения \\ РАН, ул. Амудсена, 101, Екатеринбург, Российская Федераџия
}

*Ответственный автор. Электронная почта: kru4koff@bk.ru; адрес для переписки: ул. Комсомольская, 34, Екатеринбург, Российская Федерация. Телефон: +7 (343) 374-50-51; факс: +7 (343) 374-53-30

Предложена модель композитного материала. Выполнено имитационное моделирование процесса компактирования порошкового композита состоящего из частиц титанового сплава ВТ-22 и титана марки ПТМ-1 с использованием ячейки представительного объема. Решены задачи дающие представления о формоизменении частиц и уплотнении при равномерном всестороннем и одноосном сжатии. Определены параметры модели текучести Друкера-Прагера для описания свойств порошкового композита, и с ее использованием решена задача компактирования в закрытой пресс-форме. Дается оценка “сырой” прочности брикета и описание механизма схватывания частиц при моделировании деформации ячейки представительного объема композитного материала. Для решения задач разработаны модули для гибридного моделирующего комплекса. Адекватность расчетов подтверждена проведенными экспериментами по компактированию и осадке брикетов чистых порошков и их смеси в двух соотношениях.

Ключевые слова: порошок, титан, компактирование, моделирование, схватывание частиц.

\section{1. Введение}

Порошковая металлургия является одним из экономичных методов при производстве изделий из титана и титановых сплавов для аэрокосмической и автомобильной промышленности [1]. Компактирование механической смеси порошков - один из способов получения изделий из титана, сочетающий экономичность и удовлетворительные для многих областей применения механические свойства готового изделия [2-4]. Качество готовых изделий во многом определяется на стадии компактирования, при этом прочность прессовок определяется способностью частиц схватываться между собой, это в свою очередь зависит от механических характеристик материала частиц, формы и состояния поверхности частиц порошка. При холодном компактировании порошков из высокопрочных сплавов титана с правильной сферической формой частиц даже при достаточно высоком давлении не всегда обеспечивается схватываемость частиц между собой. Получаемые компакты имеют невысокую сырую прочность и разрушение по границам частиц порошка. Повышение прочности компакта достигается созданием композита с использованием в качестве добавки более пластичного материала [5-7]. Использование дорогостоящих добавок может значительно повысить механические характеристики готового изделия, однако требуется подбор оптимального процентного содержания с точки зрения его экономической обоснованности. Для определения оптимального добавочного материала и его объемного содержания необходимо проводить достаточно большое количество экспериментов. При этом не всегда удается опробовать все материалы, которые могут использоваться в качестве добавок. Сократить количество экспериментов возможно с применением современных средств компьютерного моделирования. Моделирование процессов деформирования композитных материалов позволяет предсказывать

Kryuchkov D. I. et al. / Modelling of compaction of titanium composite powders 
механические свойства изделий до фактического производства и испытания, что снижает общую стоимость и время производственного цикла.

Для проектирования и анализа структуры композитных материалов и композиционных деталей в настоящее время создаются программные системы, предназначенные для компьютерного моделирования и инженерного анализа конструкций из композитов. Такие системы основаны на современных программах конечно-элементного анализа или являются дополнениями к ним. Современные системы инженерного анализа включают возможность создавать программные интерфейсы (модули) для параметрического решения определенной задачи. Набор программных интерфейсов, соответствующих определённым инженерным задачам, решаемых с помощью САЕ-пакета, освобождает конечного пользователя от прохождения всего технологического цикла работы с САЕ-пакетом, что существенно экономит время. Для инженерного анализа и оптимизации процессов пластического деформирования неоднородных материалов разработан ряд модулей для системы инженерного анализа Abaqus, объединенный оболочкой, - гибридный моделирующий комплекс [8].

Для решения задач механики деформирования уплотняемых материалов в САEсистемах доступны несколько моделей текучести. Однако при моделировании возникает ряд проблем, одна из которых связана с выбором реологических моделей и их идентификацией. Сложность описания реологических характеристик композитного материала еще выше и связана с тем, что частицы композита обладают различными механическими свойствами, формой и состоянием поверхности. Немаловажным аспектом является и прогноз прочностных свойств брикета после компактирования, здесь важную роль играют вопросы схватывания между частицами.

Цель данной работы - проверка применимости модели ячейки представительного объема с регулярной структурой для моделирования процесса компактирования композитного материала, в частности композита на основе порошка сплава титана ВТ-22 с различным процентным содержанием компонентов механической смеси. Данная модель отображает процесс уплотнения при равностороннем равномерном и одноосном сжатии. Для прогнозирования прочностных характеристик определяются основные закономерности и условия деформирования, необходимые для схватывания частиц между собой. Для достижения поставленной цели решены следующие задачи:

1. Построена модель представительной ячейки порошкового композита с регулярной формой для различного содержания компонентов механической смеси.

2. Осуществлено моделирование всестороннего равномерного и одноосного сжатия модели ячейки.

3. Проведены эксперименты по компактированию механической смеси с различным процентным содержанием порошков ВТ-22 и ПТМ-1.

4. С учетом экспериментальных данных определены основные факторы, определяющие схватывание частиц между собой в процессе пластического деформирования.

5. Определены параметры модели порошкового материала и осуществлено моделирование процесса компактирования.

\section{2. Материал и методика}

Сплав ВТ-22 относится к сильнолегированным высокопрочным сплавам. Частицы порошка, полученного из сплава ВТ-22 распылением плазмой, имеют форму, близкую к сферической (рис. 1 a), и гладкую поверхность с окисной пленкой в поверхностном слое. Порошок из сплава ВТ-22 не позволяет получать прессовки даже при сравнительно высоких давлениях компактирования.

Kryuchkov D. I. et al. / Modelling of compaction of titanium composite powders 


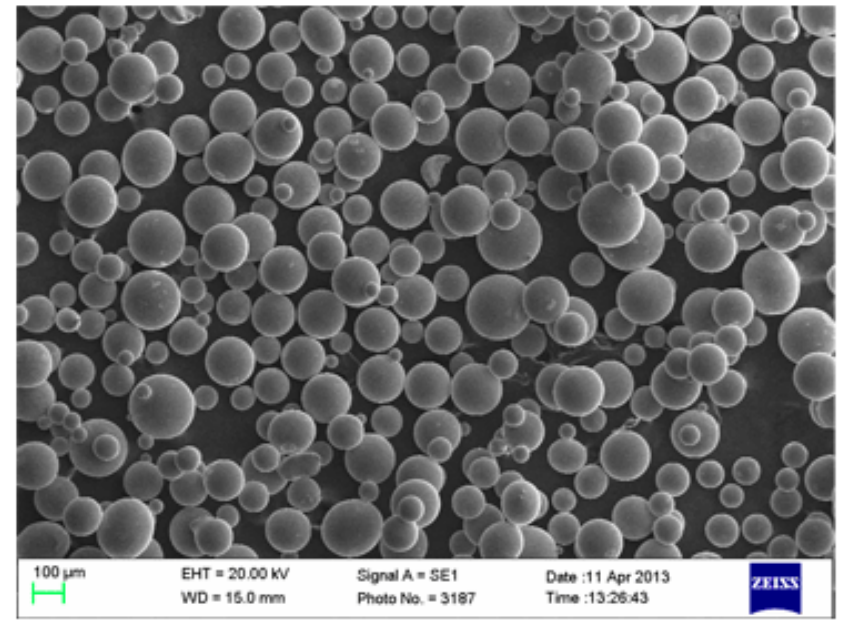

$a$

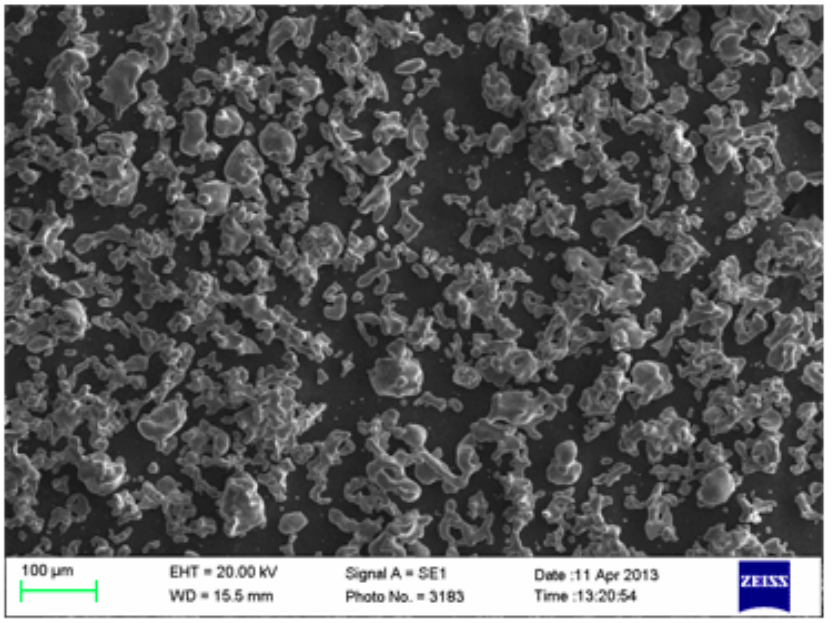

б

Рис. 1. Морфология частиц сплава титана ВТ-22 (a) и титана марки ПТМ-1 (б)

Особенность морфологии порошка ВТ-22 для обеспечения прессуемости требует внедрения в качестве добавок порошков с развитой поверхностью и более мягкими пластическими свойствами, которые должны способствовать схватыванию частиц. В качестве добавки выбран титан, полученный гидридно-кальциевым способом, - ПТМ-1, который относится к восстановленным порошкам титана и сплавов, имеющих неправильную (иррегулярную) форму (рис. 1 б) и развитую поверхность частиц, благодаря чему порошки отлично формуются при сравнительно низких давлениях компактирования.

Применение ячеек представительного объема [9-11] для идентификации реологических моделей порошкового тела описано в работах [12-13], однако данные модели применялись для монопорошков. Композиты являются гетерогенными средами, имеющими более сложную структуру и сложное поведение при пластическом деформировании, и соответственно требуется предложить новую модель ячейки. Для исследования процессов уплотнения и схватывания частиц между собой предложена модель ячейки представительного объема композита (рис. 2 a). Для упрощения, несмотря на иррегулярную форму частиц порошка ПТМ-1, в модели используется правильная сферическая форма, как и у частиц ВТ-22. Модель построена для частиц диаметром 100 мкм, так как физические эксперименты проводили на порошках ПТМ-1 и ВТ-22 фракции 100. Полученная ячейка имеет размер 100х100х100 мкм и состоит из 8 частей: $1 / 8$ каждой из частиц, по 4 частицы из материалов ВТ-22 и ПТМ-1 для моделирования состава ВТ-22(50\%)+ПТМ-1(50\%) (рис. 2 б), и 6 частиц ВТ-22 и 2 частицы ПТМ-1 для моделирования состава ВТ-22(75\%)+ПТМ-1(25\%) (рис. 2 в) В качестве идеализации принимается симметричное расположение частиц.

Начальная относительная плотность ячейки составляет $\rho_{\text {отн }}=0,524$. В случае равномерного одноосного сжатия ячейка равномерно сжимается абсолютно жесткими поверхностями до определенного перемещения с трех сторон с постоянной скоростью, остальные 3 стороны ограничены в перемещении. При одноосном сжатии ячейка сжимается с одной стороны, 5 сторон ограничены в перемещении. При этом имитируется воздействие окружающих ячейку соседних частиц при компактировании. Силы трения между площадками контакта ячейки и вспомогательными поверхностями не учитывались. Трение между частицами задавалось по закону Кулона. 


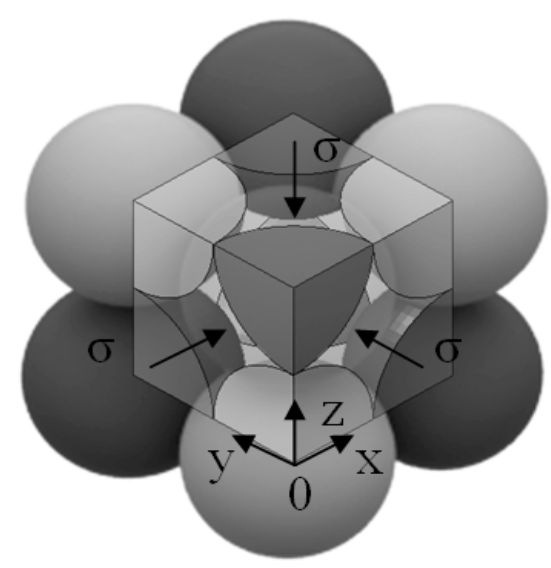

$a$

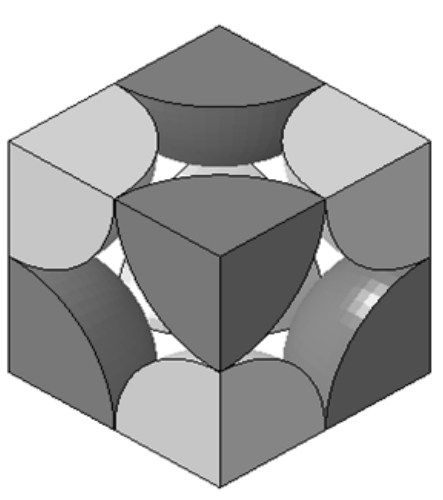

б

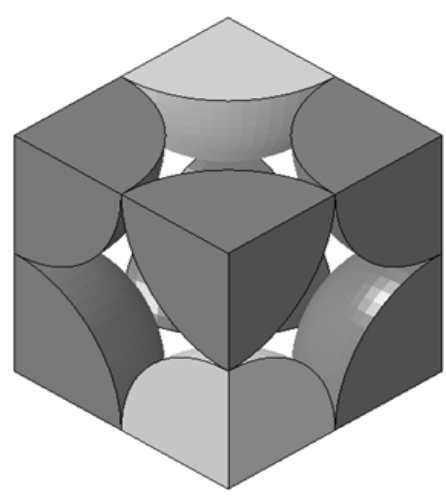

B

Рис. 2. Модель ячейки представительного объема для композита $(a)$ с содержанием

ВТ-22(50\%) + ПТМ-1(50\%) (б) с содержанием ВТ-22(75\%) + ПТМ-1(25\%) (в)

При имитационном моделировании за счёт изменения объёма пор варьируется относительная плотность в интервале $0,524 \ldots 0,995$. Относительная плотность рассчитывается через перемещение грани ячейки $u$ по формулам:

- в случае равностороннего сжатия

$$
\rho_{\text {отн }}=\frac{\pi}{6} \frac{R_{0}^{3}}{\left(R_{0}-\frac{u}{2}\right)^{3}},
$$

- в случае одноосного сжатия

$$
\rho_{\text {отн }}=\frac{\pi}{6} \frac{R_{0}}{\left(R_{0}-\frac{u}{2}\right)},
$$

где $R_{0}$ - начальный радиус частиц, $u$ - перемещение грани ячейки.

Материал частиц композита обладает упруго-пластическим свойствами. Механические свойства частиц задаются с использованием модели Джонсона-Кука [14]. Параметры модели материала определены по кривым течения из литературы [15] и с использованием подпрограммы гибридного моделирующего комплекса.

Для решения задач уплотнения, прогнозирования прочности и идентификации модели текучести композитного материала с использованием модели ячейки представительного объема разработан программный модуль для системы конечно-элементного анализа Abaqus, входящего в гибридный моделирующий комплекс.

Для описания реологического течения порошковой массы использована модифицированная модель текучести Друкера-Прагера. Использование модели текучести позволяет моделировать компактирование изделий сложной формы, определять напряженное состояние в каждой точке деформируемой заготовки, характер и картину течения материала, рассчитывать оптимальные технологические усилия. Идентификация условия текучести производилась на основе построения лемнискаты по характерным точкам, полученным посредством имитационного моделирования деформации ячейки представительного объема. Для идентификации параметров в работе использовалась методика [13]. Для определения характерных точек и описания свойств порошкового материала с использованием модифицированной мо-

Kryuchkov D. I. et al. / Modelling of compaction of titanium composite powders 
дели текучести Друкера-Прагера требуется смоделировать деформации ячейки при равномерном всестороннем и одноосном сжатии.

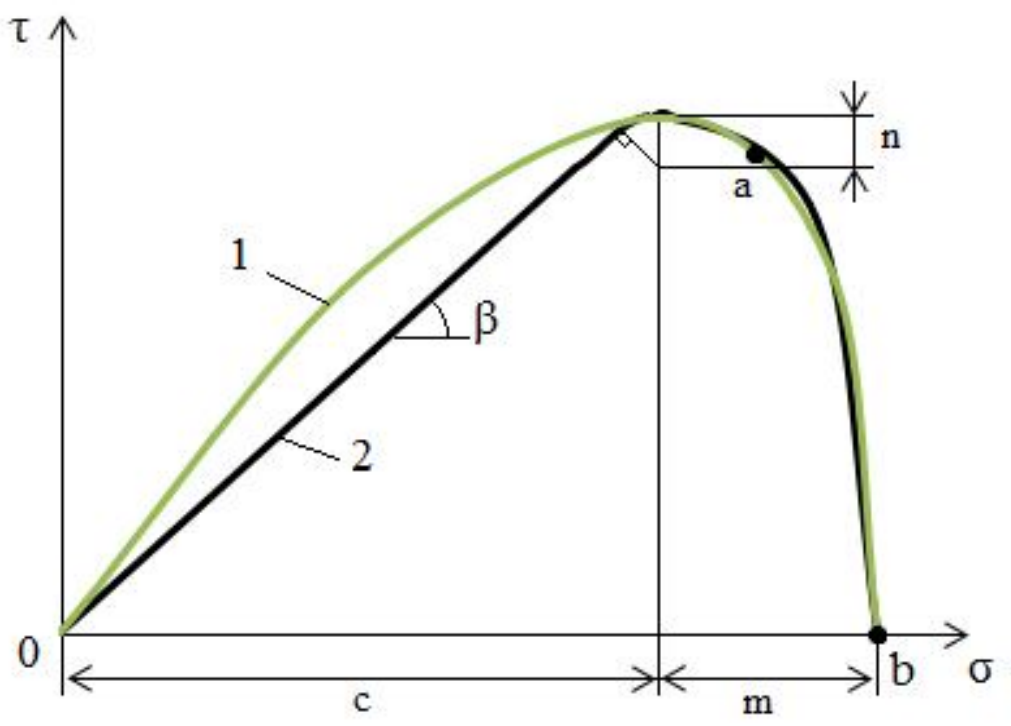

Рис. 3. Геометрическая интерпретация DPC модели в плоскости $\sigma-\tau$ порошкового материала

На рис. 3 представлена геометрическая интерпретация в плоскости $\sigma-\tau$ ( $\sigma-$ среднее нормальное напряжение, $\tau$ - интенсивность напряжений сдвига). Точки, полученные в ходе имитационного моделирования деформации ячейки представительного объема, соответствуют напряженному состоянию: $a$-одноосного сжатия, $b$ - всестороннего равномерного сжатия. По трем точкам, включая начало координат строится лемниската Бернулли. Лемниската 1 используется в качестве модели аппроксимирующей кривую текучести ДрукераПрагера 2, с точностью приемлемой для инженерных расчетов. На рис. 3 отражена отличительная особенность порошковых материалов в сравнении с пористыми материалами равенство нулю предела текучести на всестороннее растяжение.

\section{3. Результаты и обсуждение}

\section{1 Имитационное моделирование процесса деформирования ячейки композита}

На рис.4 представлены ячейки после деформации при равномерном всестороннем и одноосном сжатии. Одноосное сжатие ячейки отражает состояние частиц при компактировании в жесткой матрице. По результатам моделирования для описания свойств порошкового материала с использованием модифицированной модели текучести Друкера-Прагера определены коэффициенты для материала композитов ВТ-22+ПТМ-1 с соотношениями 50/50 и 75/25. Полученные коэффициенты приведены в табл. 1. Относительная плотность идеализированного материала варьировалась в интервале $0,6<\rho_{\text {отн }}<0,9$. 

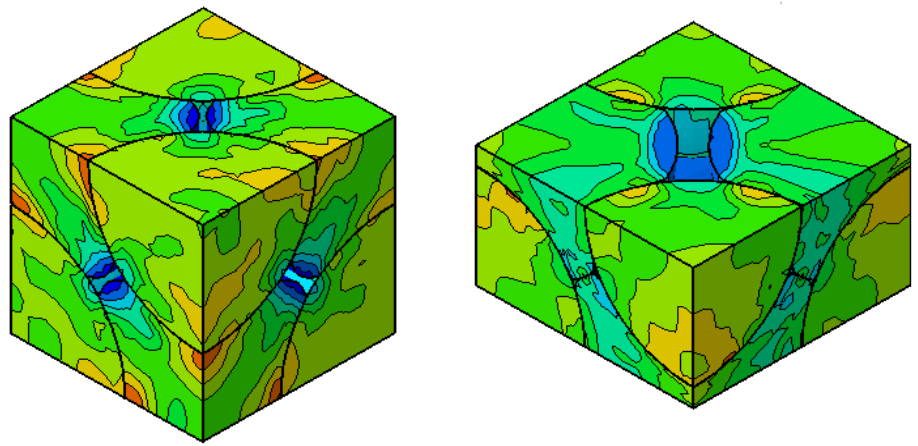

$a$
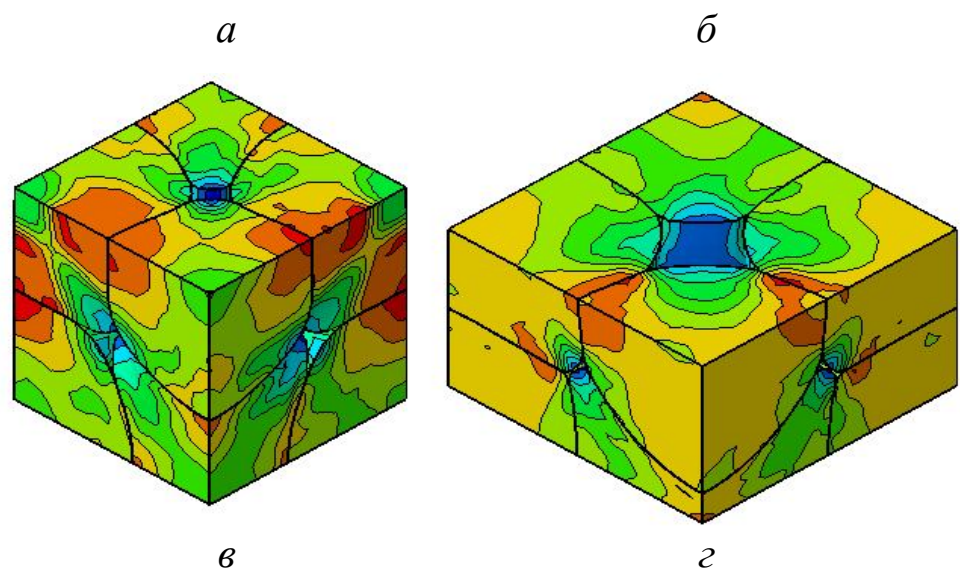

Рис. 4. Распределение среднего нормального напряжения при всестороннем равномерном ( $a$ и в) одноосном ( $\sigma$ и г) сжатии для композита с процентным содержанием ВТ-22 50\% ( $а$ и б) и 75\% (в и г)

\section{2 Моделирование процесса компактирования}

Указанные в табл. 1 параметры модели текучести использовали для задания свойств материалов при моделировании компактирования смесей 50/50 и 75/25 ВТ-22+ПТМ-1 в закрытой пресс-форме. Задача решалась в цилиндрической системе координат $r, \varphi, z$. Процесс рассматривался в осесимметричной постановке. Использована равномерная сетка четырехузловых конечных элементов.

Таблица 1 - Параметры поверхностей текучести Друкера-Прагера

\begin{tabular}{|c|c|c|c|c|c|}
\hline $\begin{array}{c}\text { Порошок ВТ- } \\
22+\text { ПТМ-1, \% }\end{array}$ & $\begin{array}{c}\text { Относительная } \\
\text { плотность } \rho_{\text {отн }}\end{array}$ & $c$ & $m$ & $\operatorname{tg} \beta$ & $n$ \\
\hline \multirow{2}{*}{$50 / 50$} & 0,9 & 371 & 166 & 0,36 & 1,79 \\
\cline { 2 - 6 } & 0,6 & 76 & 83 & 1,02 & 0,69 \\
\hline \multirow{2}{*}{$75 / 25$} & 0,9 & 388 & 176 & 0,38 & 1,93 \\
\cline { 2 - 6 } & 0,6 & 82 & 91 & 1,07 & 0,75 \\
\hline
\end{tabular}

На рис. 5 показано осевое сечение цилиндрического брикета из композита с двумя составами. Для состава 50\% ВТ-22 + 50\% ПТМ-1 среднее значение относительной плотности составляет 0,8, а для состава 75\% ВТ-22 + 25\% ПТМ-1 0,75. В горизонтальном направлении, в слое, прилегающем к деформирующему инструменту, плотность растет от центра к периферии, тогда как в слое находящемся на дне контейнера, наоборот - плотность растет от пе- 
риферии к центру. Неоднородное распределение плотности по объему брикета обусловлено затратой усилия прессования на преодоление внешнего трения прессуемой массы о контактирующие с ней поверхности элементов пресс-формы. По результатам моделирования построена зависимость средней относительной плотности от давления прессования (рис. 8).
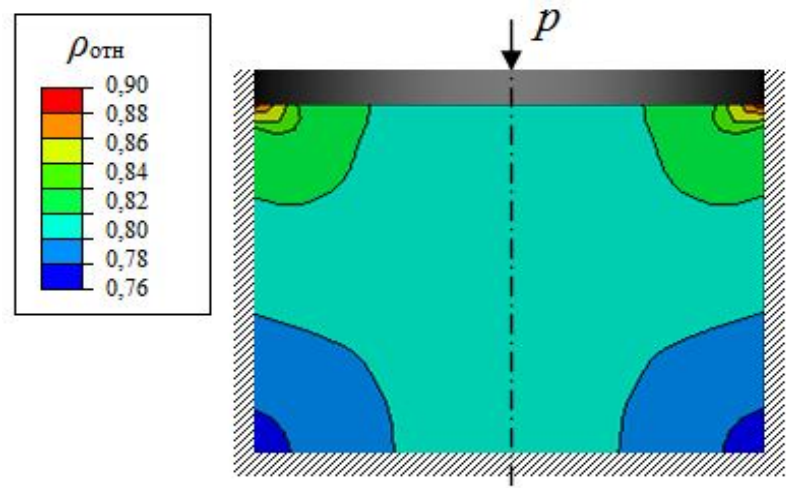

$a$
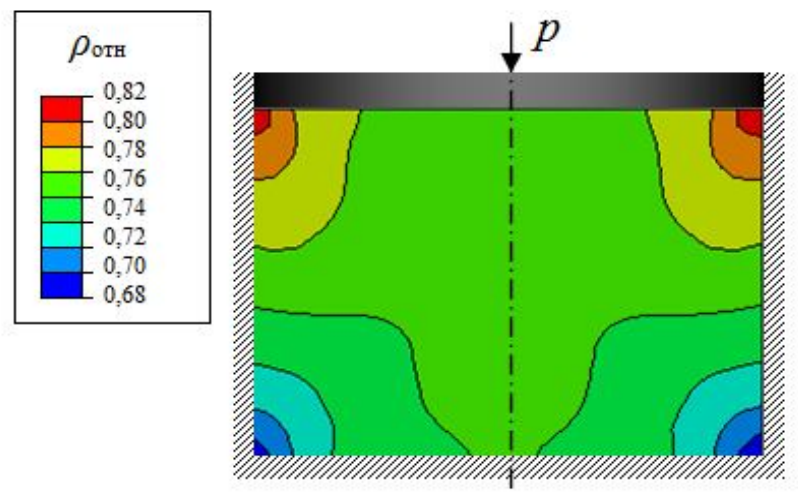

б

Рис. 5. Распределение относительной плотности в осевом сечении цилиндрического брикета из композита: $a-50 \%$ ВТ-22 + 50\% ПТМ-1, $\sigma-75 \%$ ВТ- $22+25 \%$ ПТМ-1

\section{3 Оценка прочности брикета}

Для осуществления холодной сварки металлов (схватывания), покрытых окисными или другими пленками, необходимо их разрушить и сблизить ювенильные поверхности на расстояние межатомных сил [16]. Один из возможных способов разрушения пленок - растекание поверхностей при пластической деформации. От величины деформации, предшествующей разрушению окисных пленок и последующей за ним, зависит площадь ювенильных поверхностей, а следовательно и прочность полученного соединения, определяющая качество готового изделия.

Для физического представления процесса схватывания будем считать, что каждый слой металла на своей поверхности имеет окисную пленку. Таким образом, происходит совместное деформирование слоев металлов с окисными пленками. Окисные пленки, которые подвергаются пластической деформации, обладают определенным запасом пластичности. Предполагается, что феноменологическая модель разрушения [17] справедлива и для окисной пленки. Диаграмма пластичности окисной пленки при этом зависит не только от безразмерных инвариантов тензора напряжений $\sigma / \mathrm{T}$ и $\mu_{\sigma}$, но и от толщины пленки, при этом пленка настолько тонка, что ее напряженно-деформированное состояние совпадает с таковым прилегающего металла. После того как заканчивается ресурс пластичности и значение поврежденности пленки достигает 1, окисная пленка охрупчивается, появляются макротрещины и обнажаются лежащие под слоем окисной пленки ювенильные поверхности металла.

Для того чтобы оценить прочность брикета, необходимо определить степень пластической деформации в слое оксидной пленки для каждой из частиц. При решении задачи будем считать, что толщина оксидной пленки сопоставима и равна размеру одного конечного элемента. При исчерпании ресурса пластичности оксидной пленки на одной из контактируемых частиц происходит схватывание между ними. Степень деформации, требуемую для разрушения оксидной пленки, определили при имитационном моделировании сжатия ячейки из частиц одного материала и сравнении с экспериментальными данными $[18,19]$. 

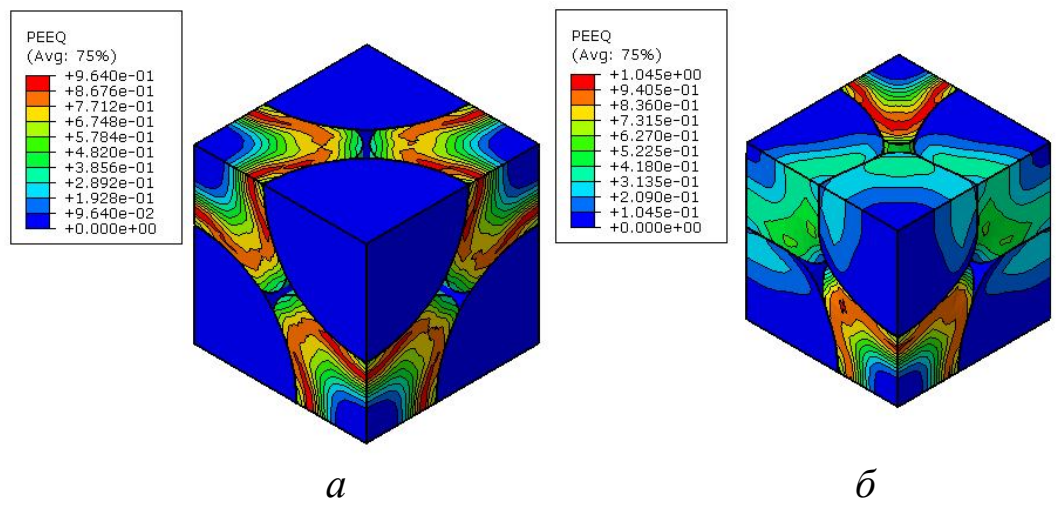

Рис. 6. Степень пластической деформации ячейки композита: $a-50 \%$ ВТ- $22+50 \%$ ПТМ-1, $\sigma-75 \%$ ВТ-22 + 25\% ПТМ-1

Имитационное моделирование показывает (см. рис. 6), что при деформации ячейки происходит равномерное растекание частиц ПТМ-1 вокруг частиц ВТ-22. Несмотря на отсутствие пластической деформации в частицах ВТ-22 степень пластической деформации частиц ПТМ-1 достаточна для разрушения окисной пленки и схватывания частиц между собой. При сжатии ячейки смеси 75/25 частицы ПТМ-1 обтекают только соседствующие с ними частицы. В области контакта частиц ВТ-22 между собой деформация недостаточна для разрушения окисной пленки, что не может способствовать образованию достаточного количества ювенильных поверхностей. Прилипание частиц в таких местах может отсутствовать.

\section{4 Экспериментальное исследование}

Для сравнения результатов имитационного моделирования провели серию экспериментов по компактированию композита ВТ-22+ПТМ-1 с процентным содержанием в смеси $50 / 50$ и 75/25. Качество брикетов после компактирования удовлетворительное, при этом в ряде случаев для образцов с содержанием ВТ-22 75\% наблюдалось осыпание нижней кромки. Компактирование брикетов проводили на гидравлическом прессе в закрытой разборной пресс-оснастке (рис. 7). При этом фиксировали усилие, действующее на пуансон, и перемещение пуансона. По усилию, действующему на пуансон, рассчитали давление. Зависимость относительной плотности от давления компактирования представлена на рис. 8. Как видно из графика, результаты моделирования, как при деформировании ячейки, так и использовании модели текучести, хорошо согласуются с экспериментальными данными. Отклонение значений, полученных при моделировании, от значений, полученных экспериментально, не превышает $5 \%$. Это доказывает возможность применения модели ячейки представительного объема для адекватного расчета при решении задачи компактирования в жесткой матрице и прогнозирования прочности изделий из композитного материала, а также идентификации модели текучести для решения задачи компактирования изделий сложной формы.

Для определения “сырой” прочности спрессованных, но не спеченных брикетов провели серию испытаний. Давление компактирования брикетов, подготовленных для испытаний, 1000 МПа. Прочность брикетов оценивали по результатам опытов на осевое сжатие (осадку) на универсальной испытательной машине. В момент начала разрушения заготовки фиксировали усилие и определяли предел “сырой” прочности на сжатие при текущей плотности $\sigma_{p}$. В результате экспериментов получены брикеты с относительной плотностью и пределом прочности на сжатие, указанными в табл. 2. Приведены составы смесей и чистых порошков, из которых получили брикеты. Брикеты из чистого ВТ-22 после компактирования рассыпались. В отличие от ВТ-22 порошок ПТМ-1 отлично прессуется, полученные брикеты имели плотность, близкую к теоретической, и относительно высокую “сырую” прочность. 


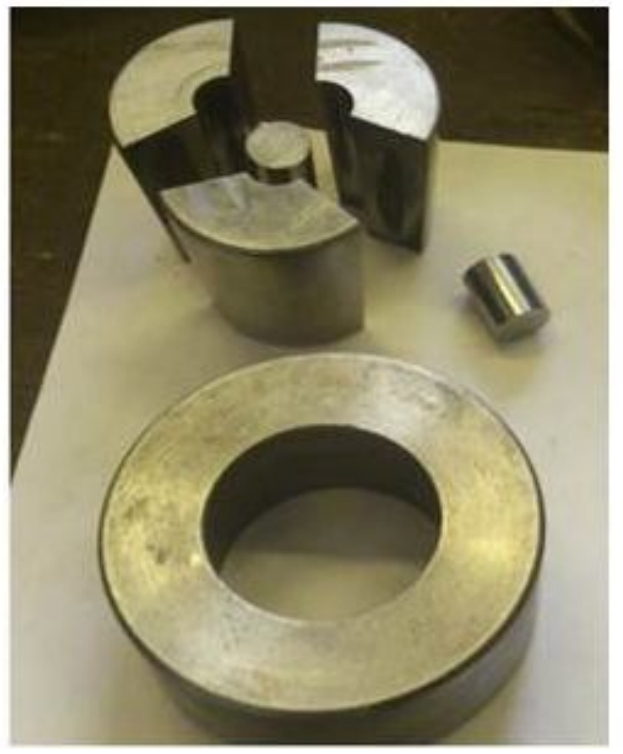

$a$

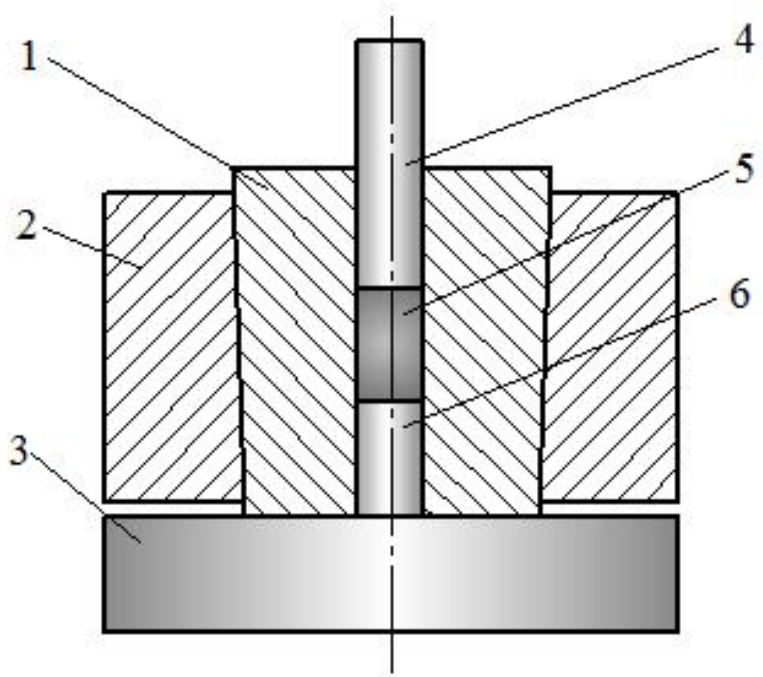

$\sigma$

Рис. 7. Общий вид $(a)$ и схема (б) пресс-оснастки для брикетирования металлических порошков. 1 - контейнер, 2 - корпус, 3 -плита, 4 - пуансон, 5 - порошок, 6 - заглушка

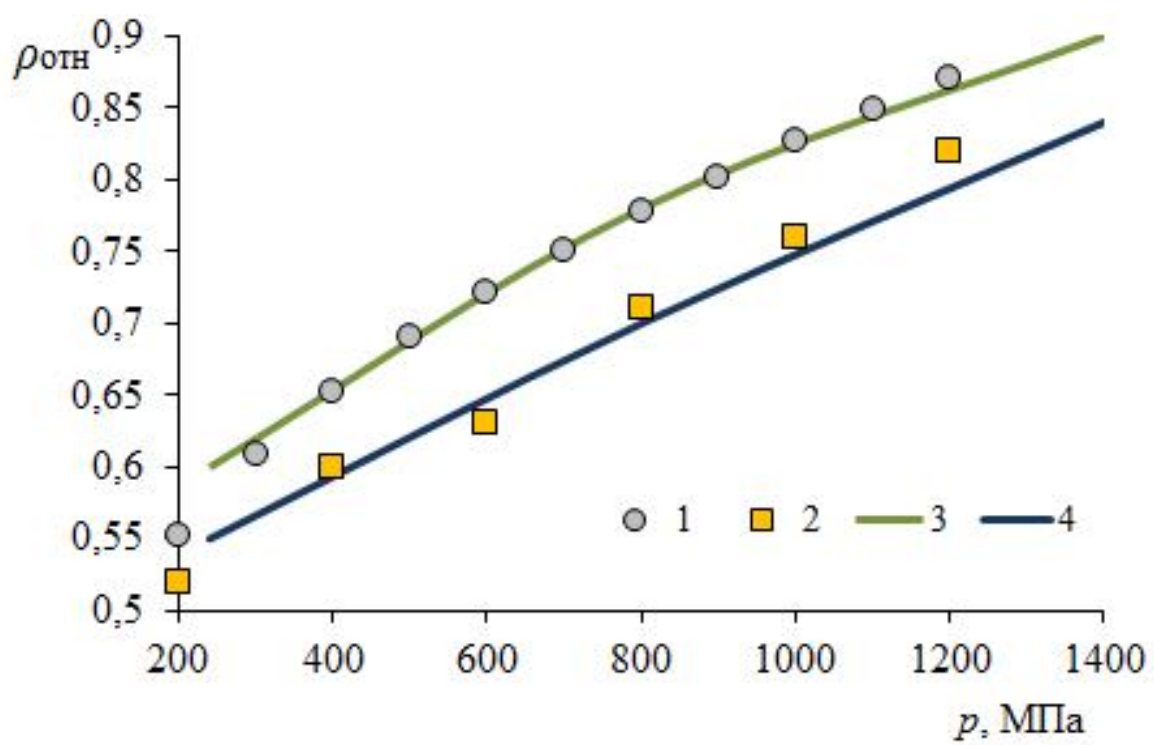

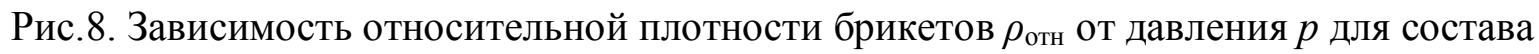
ВТ-22(50\%)+ПТМ-1(50\%): 1 - эксперимент, 3 - моделирование компактирования; для состава ВТ-22(75\%)+ПТМ-1(25\%): 2 - эксперимент, 4 - моделирование компактирования

Таблица 2 - Относительная плотность и предел “сырой” прочности на сжатие

\begin{tabular}{|c|c|c|c|c|}
\hline \multirow{2}{*}{$№$} & \multicolumn{2}{|c|}{ Состав, мас.\% } & \multirow{2}{*}{$\rho_{\text {отн }}$} & \multirow{2}{*}{$\sigma_{p}$, МПа } \\
\cline { 2 - 3 } & $\mathrm{BT-22}$ & ПТМ-1 & \\
\hline 1 & 50 & 50 & 0,81 & 2,83 \\
\hline 2 & 75 & 25 & 0,76 & 0,47 \\
\hline 3 & 100 & - & - & - \\
\hline 4 & - & 100 & 0,986 & 7,54 \\
\hline
\end{tabular}

Полученные брикеты из смеси 50/50, в отличие от смеси 75/25, имели немного выше относительную плотность и более высокий предел прочности. Разница между относительной плотности и прочности брикетов двух смесей объясняется с помощью имитационного моде-

Kryuchkov D. I. et al. / Modelling of compaction of titanium composite powders 
лирования. В смеси 50/50 твердые частицы ВТ-22 не деформируются и следовательно требуется меньшее усилие для достижения равной относительной плотности. Так как образцы компактировлись при одинаковом усилии, брикеты из смеси 50/50 получились с большей относительной плотностью. В составе 75/25 частицы ВТ-22 деформируются, но не сцепляются между собой, что, по-видимому, обусловлено правильной формой частиц и наличием оксидной пленки с высоким ресурсом пластичности на поверхности частиц.

\section{4. Заключение}

Выполнено имитационное моделирование процесса компактирования порошкового композита, состоящего из частиц титанового сплава ВТ-22 и титана марки ПТМ-1 с использованием ячейки представительного объема. Решены задачи, дающие представления о формоизменении частиц и уплотнении при равномерном всестороннем и одноосном сжатии. Задачи решены с использованием разработанного модуля для гибридного моделирующего комплекса, построенного на базе системы инженерного анализа Abaqus. Показано, что увеличение процентного содержания ВТ-22 более 50\% в смеси не обеспечивает равномерного растекания более пластичной компоненты в виде порошка ПТМ-1. Механические характеристики и сферическая форма частиц порошка ВТ-22, а также твердая оксидная пленка на поверхности частиц с большим ресурсом пластичности препятствует схватыванию частиц между собой. Это приводит к ухудшению качества и уменьшению прочности не спеченного изделия. Результаты моделирования деформирования ячейки представительного объема позволили идентифицировать параметры модели текучести Друкера-Прагера для порошкового композита смеси ВТ-22 и ПТМ-1 с соотношением 50/50 и 75/25. С использованием полученных коэффициентов модели текучести решены задачи компактирования в закрытой прессформе. Для подтверждения адекватности решений, полученных с помощью имитационного моделирования, представлены результаты экспериментов по компактированию и осадке брикетов чистых порошков и их смеси в двух соотношениях. Полученное решение отражает возможность использования модели ячейки представительного объема для прогнозирования прочности и идентификации модели текучести композитного материала.

\section{Литература}

1. Froes F. H., Smugersky J. E. Poweder metallurgy of titanium alloys. - The metallurgical society of AIME Publ., 1980. - 263 p.

2. Froes F. H., Eylon D., Bomberger H. B. Powder metallurgy of titaniumium alloys - a review // Titanium Technology: Present Status and Future Trends. - 1985. - P. 49-59.

3. Abkowitz S., Abkowitz S.M., Weihrauch P.F., Wells M.G. Low cost PM manufacture of titanium alloy components for fatique critical application. Proc. The Third International Conference on Powder Metallurgy in Aerospace, Defense, and Demanding Applications, Princeton, NJ, 1993, pp. 241.

4. Moxson V. S., Senkov O. N., Froes F. H. Production and applications of low cost titanium powder products // The International Journal of Powder Metallurgy. - 1998. - Vol. 34 (5). - P. 45-53.

5. Kari S. Computational evaluation of effective material properties of composites reinforced by randomly distributed spherical particles // Composite Structures. - 2007. - Vol. 77. - P. 223-231.

6. Mesarovic S. D. Micromechanical modelling of the compaction of low density composite powders // Metalurgija - Journal of Metallurgy. - 2005. - Vol.11 (1). - P. 1-21.

7. Sridhar I., Fleck N. A. Yield behaviour of cold compacted composite powders // Acta materialia. - 2000. - Vol. 48. - P. 3341-3352.

8. Крючков Д. И., Залазинский А. Г. Гибридный моделирующий комплекс для оптимизации процессов прессования неоднородных материалов // Вестник компьютерных и информационных технологий. - 2013. - № 9. - С. 22-28. 
9. Leon L., Mishnaevsky Jr. Automatic voxel-based generation of 3D microstructural FE models and its application to the damage analysis of composites // Materials Science and Engineering. 2005. - Vol. 407. - P. 11-23.

10. Shen H., Brinson L. C. Finite element modeling of porous titanium // International Journal of Solids and Structures. - 2007. - Vol. 44. - P. 320-335.

11. Kushch V. I., Podoba Ya. O., Shtern M. B. Effect of micro-structure on yield strength of porous solid: A comparative study of two simple cell models // Computational Materials Science. 2008. - Vol. 42. - P.113-121.

12. Ogbonna N., Fleck N. A. Compaction of an array of spherical particles // Acta Metallurgica et Materialia. - 1995. - Vol. 43. - P. 603-620.

13. Березин И. М., Залазинский А. Г. Определение условий пластического течения некомпактных материалов // Фундаментальные исследования. - 2013. - № 8. Ч. 1. - С. 19-23.

14. Johnson G. R, Cook W. H. Fracture Characteristics of Three Metals Subjected to Various Strains, Strain Rates, Temperatures and Pressures // Eng. Fract. Mech. - 1985. - Vol. 21. - P. 31-48.

15. Богатов А. А. Механические свойства и модели разрушения металлов. - Екатеринбург: ГОУ ВПО УГТУ-УПИ, 2002. - 329 с.

16. Семенов А. П. Схватывание металлов. - М.: Машгиз, 1958. - 280 с.

17. Колмогоров В. Л. Механика обработки металлов давлением. - Екатеринбург: УГТУ-УПИ, 2001. - $836 \mathrm{c.}$

18. Колмыков В. Л., Глазунова М. Ю., Залазинский А. Г. Волочение тонкой проволоки из титана для шовных материалов // Известия ВУЗов. Цветная металлургия. - 2002. - № 3. - С. 66-69.

19. Колмыков В. Л., Залазинский А. Г. Нанесение оксидных покрытий для волочения проволоки из труднодеформируемых материалов // Упрочняющие технологии и покрытия. 2007. - № 6. - C. 15-18. 